\title{
Ovarian Development of the Mud Crab Scylla paramamosain in a Tropical Mangrove Swamps, Thailand
}

\author{
M. S. Islam ${ }^{1}$, K. Kodama ${ }^{2}$, and H. Kurokura ${ }^{3}$ \\ ${ }^{1}$ Department of Aquaculture and Fisheries, Jessore Science and Technology University, Jessore- \\ 7407, Bangladesh \\ ${ }^{2}$ Marine Science Institute, The University of Texas at Austin, Channel View Drive, Port Aransas, \\ Texas 78373, USA \\ ${ }^{3}$ Laboratory of Global Fisheries Science, Department of Global Agricultural Sciences, The \\ University of Tokyo, Bunkyo, Tokyo 113-8657, Japan
}

Received 15 October 2009, accepted in revised form 21 March 2010

\begin{abstract}
The present study describes the ovarian development stages of the mud crab, Scylla paramamosain from Pak Phanang mangrove swamps, Thailand. Samples were taken from local fishermen between June 2006 and December 2007. Ovarian development was determined based on both morphological appearance and histological observation. Ovarian development was classified into five stages: proliferation (stage I), previtellogenesis (II), primary vitellogenesis (III), secondary vitellogenesis (IV) and tertiary vitellogenesis (V). The formation of vacuolated globules is the initiation of primary vitellogenesis and primary growth. The follicle cells were found around the periphery of the lobes, among the groups of oogonia and oocytes. The follicle cells were hardly visible at the secondary and tertiary vitellogenesis stages. Yolk granules occurred in the primary vitellogenesis stage and are first initiated in the inner part of the oocytes, then gradually concentrated to the periphery of the cytoplasm. The study revealed that the initiation of vitellogenesis could be identified by external observation of the ovary but could not indicate precisely.
\end{abstract}

Keywords: Ovarian maturation; Ovarian histology; Mud crab; Scylla paramamosain.

(C) 2010 JSR Publications. ISSN: 2070-0237 (Print); 2070-0245 (Online). All rights reserved.

DOI: $10.3329 /$ jsr.v2i2.3543

J. Sci. Res. 2 (2), 380-389 (2010)

\section{Introduction}

Mud crabs of the genus Scylla are commercially important crustaceans, are traditionally exploited by artisanal fishermen [1] and provide a basic source of income for coastal fishing communities throughout the Indo-Pacific region, especially in Thailand [2]. Four species of the genus Scylla are revised [3]; Scylla serrata, S. paramamosain, S. olivacea

\footnotetext{
${ }^{1}$ Corresponding author: tuhinkk@yahoo.com
} 
and S. tranquebarica, of which S. olivacea, S. paramamosain and S. serrata have been recorded in Thailand. Though S. olivacea reported as the most common species [4], $S$. paramamosain also exists as co-existence and in equal proportion in some areas in Thailand $[5,6]$.

In spite of abundance and commercial importance of the genus Scylla, there is a paucity of information on the ovarian development and oogenesis of the particular species S. paramamosain. Previous studies of the genus Scylla focused on the ovarian development and oogenesis: S. serrata [7-10]; S. olivacea [11] but no studies yet considered the species S. paramamosain. Roberton and Kruger [8] classified the ovarian development in wild S. serrata into six stages where as Quintino et al. [10] classified as five stages based on external and histological characteristics.

The color of ovaries changes transparent to yellow to deep orange with the progression of maturation of ovary for the species of S. serrata [8-10] and S. olivacea [11]. However, Robertson and Kruger [8] mentioned that ovarian color is not strictly to body size. Therefore, color changes with ovaries maturation and ovarian development stages for the specific-species is necessary. This is the first ever attempt to describe ovarian development of the species S. paramamosain.

The present study examined ovarian development and describes the stages based on the external and histological characteristics of the ovary of wild S. paramamosain. Moreover, a change of abdominal shape with the maturation progressed was compared based on the histological observation.

\section{Materials and Methods}

The Pak Phanang estuary is located in Nakhon Si Thamarat province, on the east coast of southern Thailand $\left(8^{\circ} 9^{\prime}-11^{\prime} \mathrm{N}\right.$ and $\left.100^{\circ} 9^{\prime}-18^{\prime} \mathrm{E}\right)$. The eastern half of the estuary is fringed by a wide mangrove forest (approximately 9,000 hectares), which is associated with an extensive mud flat (1-3 km wide) that emerges at low tide. There are three distinct seasons: hot-dry season (February-May), rainy season (June-September) and the highest rainfall period of monsoon season (October-January) with water temperature ranging $25-36^{\circ} \mathrm{C}$ [12]. Average annual rainfall ranges about 2,000-3,000 $\mathrm{mm}$ and salinity fluctuates between $1-25$ ppt [13].

Crab fishing is conducted throughout the year within mangrove channels as well as associated channels connected to the bay. Mud crabs of the genus Scylla are fished by crab-baited trap, channel trap or caught by bare hand using a metal hook. We collected Scylla paramamosain from the local crab fishers in June, October and November in 2006 and April, May and December in 2007. Live specimens were brought back to the laboratory and were ice-shocked at the time of measurement for further dissection. The abdominal shape of the genus Scylla changes with pubertal (or maturity) molt [7]. We defined three categories of the abdominal shape: narrow and triangular shaped (V-shape), wide and globular shaped abdomen with darkened color (U-shape), and intermediate between the $\mathrm{V}$ and $\mathrm{U}$-shapes (intermediate) (Fig. 1). We recorded the category of the 
abdominal shape for each specimen. A small portion of ovary was fixed in Davidson's fixation for further histological study.

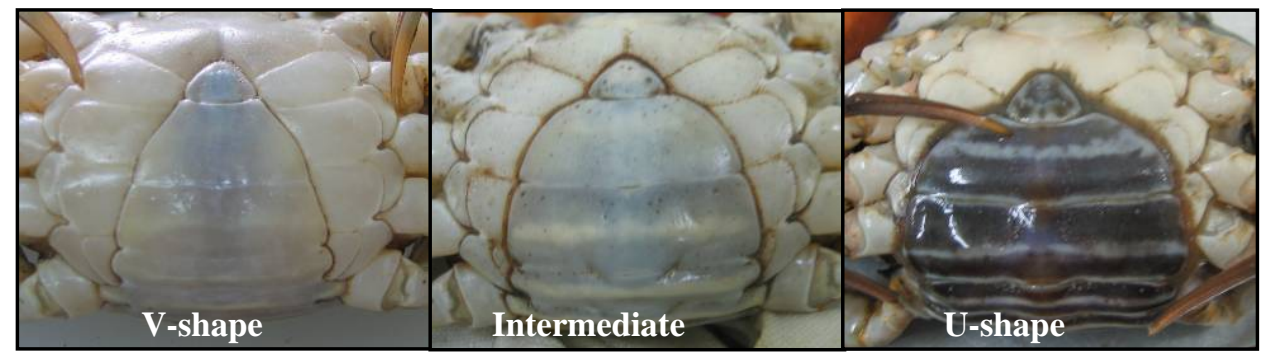

Fig. 1. Three types of the abdominal shape of female Scylla paramamosain; narrow and triangular shaped (V-shape), wide and globular shaped abdomen with darkened color (U-shape), and intermediate between the $\mathrm{V}$ and $\mathrm{U}$-shapes (intermediate).

Tissue from the middle of the left ovarian lobe of female $S$. paramamosain $\geq 70 \mathrm{~mm}$ internal carapace width (ICW) was dissected for histological examination. Crabs $<70 \mathrm{~mm}$ ICW is considered as juvenile for the present study which proposed for the species $S$. olivacea [14]. The tissues were dehydrated in ascending ethanol concentrations from 70 to $100 \%$, transferred to lemosol (Wako Pure Chemical Industries, Osaka, Japan) and embedded in paraffin. The tissues were sectioned to $5 \mu \mathrm{m}$ and stained with Mayer's hematoxylin-eosin. The developmental stage of the oocyte was determined histologically by making reference to those of other crustaceans $[8,11,15-18]$.

\section{Results}

A total of 60 female crabs ( $\geq 70 \mathrm{~mm}$ ICW) were assessed to observe the ovarian condition according to the abdominal shape as well as histological dissection of the ovary. In abdominal shape pattern, $48 \%, 12 \%$, and $40 \%$ specimens were under the categories of immature, intermediate and mature respectively.

The progress of ovarian maturation was classified into five stages based on external characters and the presence of the most advanced oocytes with the histological observation (Table1 and Figs. 2 and 3).

The immature or proliferation ovary (stage I) showed transparent to translucent color that was sometimes difficult to recognize and separate from the digestive gland. Stage I ovary was made up of oogonia that concentrated mostly at the periphery of the ovary (Fig. 2A). Each oogonium $(5-10 \mu \mathrm{m})$ is spherical in shape and the cytoplasm is hardly visible (Fig. 3A). 
Table 1. Morphological and histological characteristics of the ovary development stages of Scylla paramamosain collected at Pak Phanang mangrove swamps, Thailand.

\begin{tabular}{|c|c|c|}
\hline Stage & Morphological characteristics & Histological characteristics \\
\hline I: Proliferation & $\begin{array}{l}\text { Translucent ovary showing ribbon- } \\
\text { like structure. }\end{array}$ & $\begin{array}{l}\text { Oocyte diameter } 35-50 \mu \mathrm{m} \text {. Presence } \\
\text { of cluster of oogonia in the ovarian } \\
\text { lobe. }\end{array}$ \\
\hline $\begin{array}{l}\text { II: Pre- } \\
\text { vitellogenesis }\end{array}$ & $\begin{array}{l}\text { Off white to creamy white ovary. } \\
\text { Approximately } 2-3 \mathrm{~mm} \text { thick and } \\
\text { which occupy } 1-2 \% \text { of the cavity. }\end{array}$ & $\begin{array}{l}\text { Oocyte diameter } 45-100 \mu \mathrm{m} \text {. Visible } \\
\text { of vacuolated globules and follicle } \\
\text { cells. }\end{array}$ \\
\hline $\begin{array}{l}\text { III: Primary } \\
\text { vitellogenesis }\end{array}$ & $\begin{array}{l}\text { Ovary turns to pale or light yellow } \\
\text { color, } 3-7 \mathrm{~mm} \text { thick and occupy } 10- \\
20 \% \text { of the cavity. }\end{array}$ & $\begin{array}{l}\text { Oocyte diameter } 80-150 \mu \mathrm{m} \text {. } \\
\text { Appearance of yolk globules. }\end{array}$ \\
\hline $\begin{array}{l}\text { IV: Secondary } \\
\text { vitellogenesis }\end{array}$ & $\begin{array}{l}\text { Yellow to orange ovary that are } 7-12 \\
\text { mm thick and occupy } 20-75 \% \text { of the } \\
\text { cavity. }\end{array}$ & $\begin{array}{l}\text { Oocyte diameter } 120-200 \mu \mathrm{m} \text {. Yolk } \\
\text { globules occupied the enter } \\
\text { cytoplasm. }\end{array}$ \\
\hline $\begin{array}{l}\text { V: Tertiary } \\
\text { vitellogenesis }\end{array}$ & $\begin{array}{l}\text { Individual eggs are visible. Yellow } \\
\text { orange to red orange ovary; } 10-20 \\
\text { mm thick and occupy }>75 \% \text { of the } \\
\text { cavity. }\end{array}$ & $\begin{array}{l}\text { Oocyte diameter } 150-250 \mu \mathrm{m} \text {. } \\
\text { Nucleus barely visible. }\end{array}$ \\
\hline
\end{tabular}

The developing or previtellogenic ovary (stage II) form as two lines on the upper portion of digestive gland and was easily differentiated from the gland (Fig. 2B). In the stage II ovary, started to form primary oocytes including the presence of vacuolated globules in the cytoplasm and follicle cells on the periphery of the cytoplasm (Fig. 3B).

The early developing or primary vitellogenesis stage is the initiation of vitellogenesis. The ovary changes to yellow coloration (Fig. 2C). The vacuolated globules disappeared from the cytoplasm. Small yolk globules started to appear from periphery of the cytoplasm of the oocytes but did not occupy the entire cytoplasm (Fig. 3C).

During the Late-maturing or secondary vitellogenic (stage IV) stage, the lobules were developed prominently in sterno carapace and upper digestive gland (Fig. 2D). In this stage, the oocyte grows rapidly $(120-200 \mu \mathrm{m})$ and the nucleus reached maximum (30-40 $\mu \mathrm{m})$ at this stage or at the end of primary vitellogenesis. Irregular shaped cytoplasm with larger globular inclusions found towards the periphery, while follicle cells were hardly visible (Fig. 3D).

In the mature or tertiary vitellogenesis stage (stage V), the ovary enlarged to the maximum and eventually covered the hepatopancreas and the majority of the cardiac stomach (Fig. 2E). The yolk globules partly fused to one another (Fig. 3E).

In this study, we did not find crabs with ovaries containing ovulated and/or atretic oocytes. Among the sample population, most females $(60 \%)$ belonged to the ovarian developmental stage I, whereas only $3 \%$ belonged to stage $\mathrm{V}$.

Females classified as $\mathrm{V}$-shape and intermediate in the abdominal shape had immature ovaries (stages I-II). In females with U-shaped abdomen, $57 \%$ of the specimens had a 
vitellogenic ovary (stages III-V), but the remaining $43 \%$ were classified as immature (stages I-II; Fig. 4).
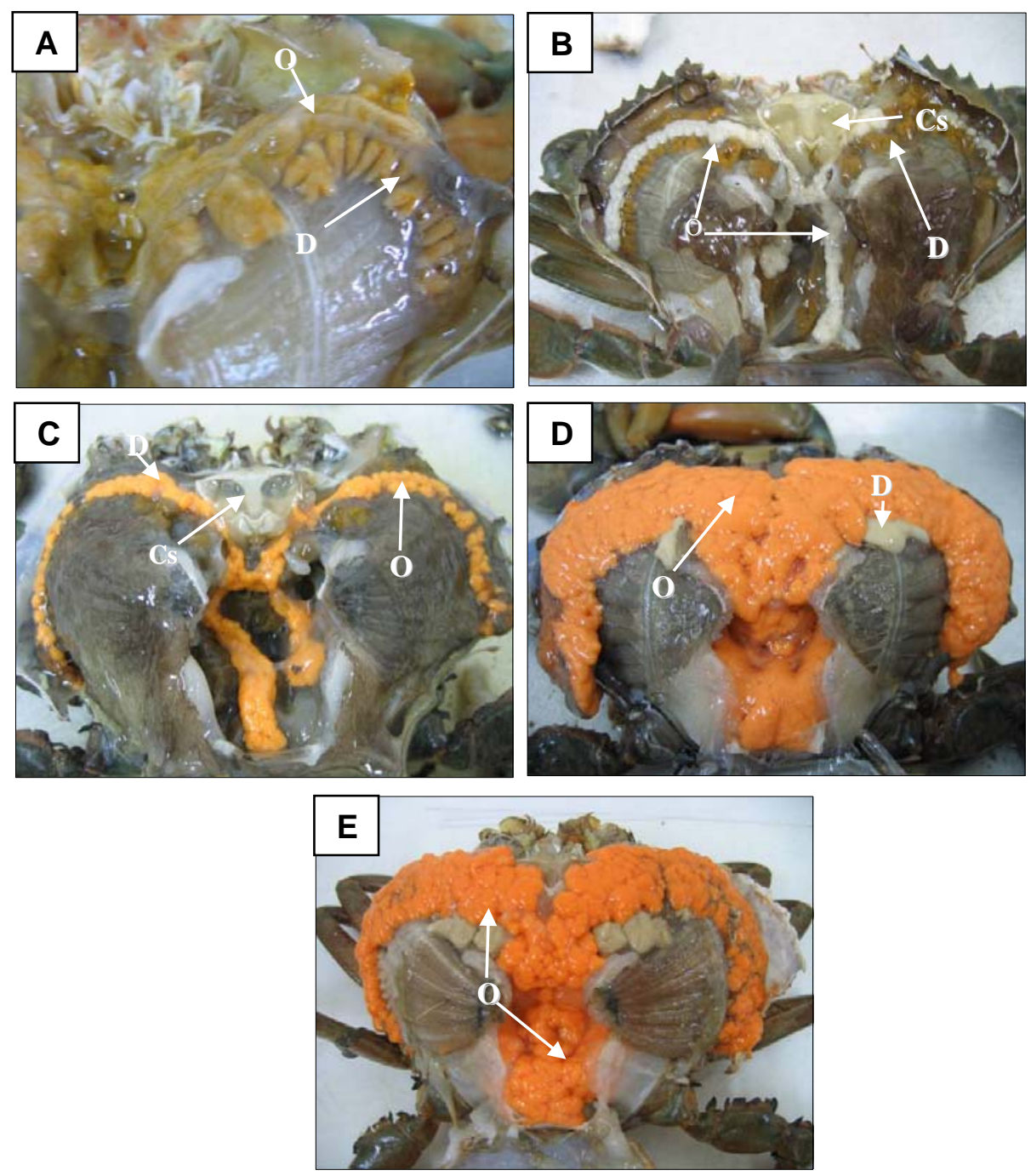

Fig. 2. External observation of ovary of Scylla paramamosain in Pak Phanang mangrove swamps, Thailand. Five ovarian developmental stages determined from both external observations are shown. A: Immature; B: developing; C: early maturing; D: late maturing and E: maturation. Cs, cardiac stomach; D, digestive gland; O, ovary. 

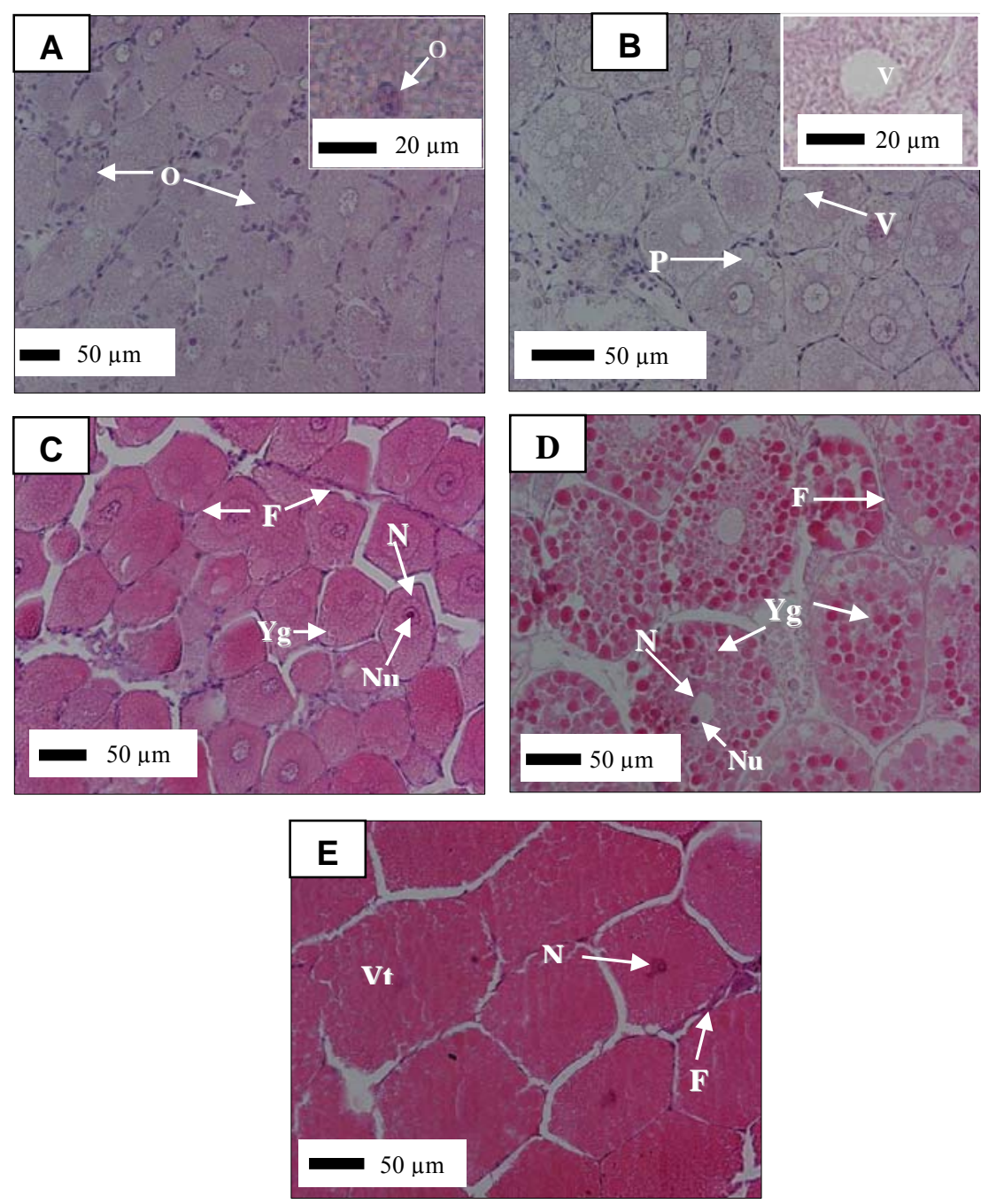

Fig. 3. Ovarian development of Scylla paramamosain in Pak Phanang mangrove swamps, Thailand. Five ovarian developmental stages based on the histological examination are shown. A: proliferation (Inset: higher magnification of oogonium); B: previtellogenesis (Inset: higher magnification of vacuolated globule); $\mathrm{C}$ : primary vitellogenesis; $\mathrm{D}$ : secondary vitellogenesis and $\mathrm{E}$ : tertiary vitellogenesis. All samples were stained with Mayer's hematoxylin-eosin. F, follicle cell; N, nucleus; $\mathrm{Nu}$, nucleolus; O, oogonium; P, primary oocytes; Yg, yolk globule; V, vacuolated globule; Vt, vitellus.

The relationship between gonad somatic index (GSI) and each ovarian developmental stage is shown in Table 2. GSI remained low at stages I and II and began to increase after yolk accumulation started at stage III. Mature ovaries at stage V showed the highest mean GSI of more than $10 \%$. 
Table 2. Frequency distribution of GSI and mean and standard deviation (SD) of GSI for each ovarian developmental stage of female Scylla paramamosain in Pak Phanang mangrove swamps. Juvenile females $<70 \mathrm{~mm}$ internal carapace width were not considered.

\begin{tabular}{lrrccc}
\hline \multirow{2}{*}{ GSI (\%) } & \multicolumn{5}{c}{ Frequency (\%) } \\
\cline { 2 - 6 } & Stage I & Stage II & Stage III & Stage IV & Stage V \\
\hline$<1$ & 93 & 40 & 0 & 0 & 0 \\
$1-5$ & 7 & 60 & 88 & 0 & 0 \\
$6-10$ & 0 & 0 & 13 & 75 & 50 \\
$>10$ & 0 & 0 & 0 & 25 & 50 \\
No. of samples & 36 & 10 & 8 & 4 & 2 \\
Mean GSI (\%) & 0.7 & 1.1 & 3.2 & 8.3 & 10.7 \\
SD & 0.4 & 0.4 & 1.6 & 2.7 & 4.6 \\
\hline
\end{tabular}

\section{Discussion}

The present study is the first report investigating ovarian developmental stages of $S$. paramamosain on the basis of both external and histological observations of the ovary. The ovarian developmental stages (I-V) based on external appearance are resemble to the histological observation. The diameter of the oocyte increased as the ovarian developmental stage progressed, resulting in an increase in the volume of the ovary as shown by both the GSI increment and external observation of the ovary. The general histological features regarding formation of oogenesis and ovarian development stages of S. paramamosain are similar to those of S. serrata $[7,8,9,10]$, S. olivacea [11] and other brachyuran crabs; e.g., blue swimmer crab Portunus pelagicus [19], swimming crab Portunus trituberculatus [20].

The major phases of oogenesis in brachyuran crabs are described by Cheng [21]. These can be divided into two: the previtellogenic phase, which contains essentially primary oocytes, and the vitellogenic phase, in which oocytes increase in size as yolk globules appear in the cytoplasm. The developing oocytes and the follicle cells are the major cell types within the ovarian lobes of Scylla spp. Follicle cells are larger and more obvious in immature gonad, which is similar to those observed in S. serrata [10]; S. olivacea [11] and in blue crab [22]. In the progress of further maturation, the follicle cells surround each oocytes are flattened. Follicle cells might be related to ovarian yolk synthesis in S. paramamosain as reported in other crustaceans; e.g., Marsupenaeus japonicus [23]; Oratosquilla oratoria [18].

Vacuolated globules were noticed in the cytoplasm of oocytes before initiation of vitellogenesis, which were shown to be oil globules in other crustaceans $[10,11,15,18]$. Yano [22] suggested that oil globules are functionally related to the accumulation of yolk protein in prawns and crabs. In brachyuran crabs, cytoplasm changes from basophilic to acidophilic after oil globules move to the periphery of the oocyte and diffuse [15]. In $S$. paramamosain, large vacuolated globules in the oocytes in previtellogenic ovaries were observed which disappeared after the initiation of vitellogenesis, suggesting that the vacuolated globules were oil globules. 
In the present study, we did not observe individuals with ovulation and/or atretic stage ovaries. Thus, the absence of spawning and post-spawned females in the near-shore mangrove regions, and the small frequencies of females with tertiary vitellogenic ovaries suggested the occurrence of a spawning migration to offshore regions. This phenomenon has been reported previously in Thailand $[5,14]$. However, it is necessary to collect females just prior to and/or after the spawning from offshore regions to validate the relationship between gonadal maturation and spawning migration.

It is showed that the color of the immature ovaries is translucent to yellow and becomes orange in mature ovaries. Ovaries particularly in mature or tertiary vitellogenesis stage were yellow to orange not deep or black orange except one crab in the present study. However, for the other two studied species, S. serrata [10] and S. olivacea [11] showed deep orange in mature stage. The phenomena of changing coloration in ovaries due to accumulation of yolk in the oocytes [10] which serves as the source of nutrition for the developing embryo in crustacean. Yolk granules of S. paramamosain begin to accumulate from the periphery of the oocyte which is similar to other crab species ( $R$. ranina, [15]; $S$. serrata, [10]; S. olivacea, [11]).

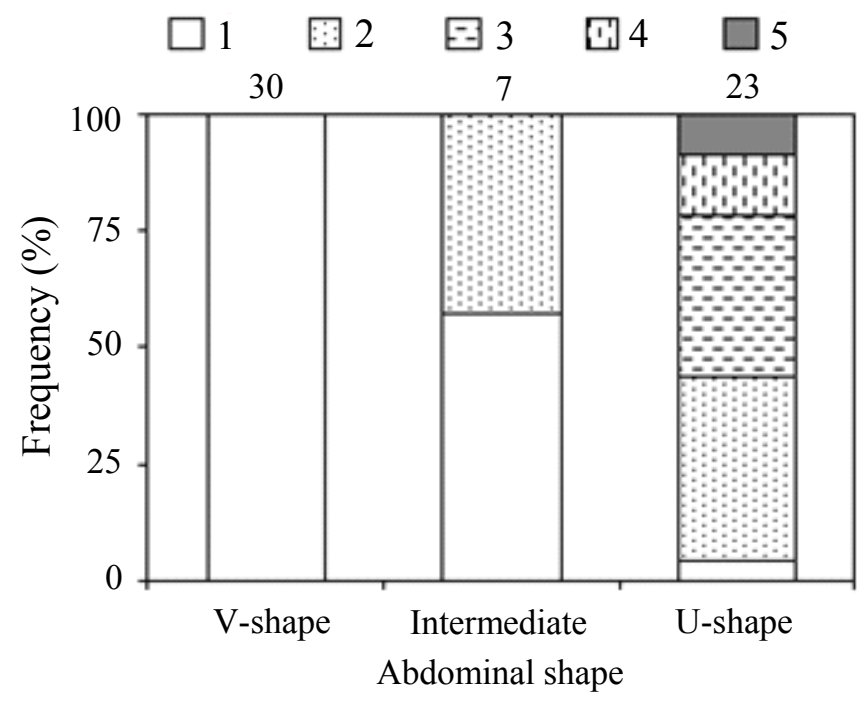

Fig. 4. Frequency of occurrence of each ovarian developmental stage for three categories of the abdominal shape of female Scylla paramamosain. The classification of the developmental stages of ovary is same as Fig. 3. Numbers on each column indicate sample size.

Overton and Macintosh [5] used the pubertal molt as a morphological indicator of ovarian maturity with the shape of abdomen. In the present study, the comparison of abdominal shape and ovarian maturation stage on the basis of histological observation showed that the intermediate crabs were not gone to the vitellogenic stage (III) ovary 
which indicates all intermediate crabs are immature female. On the other hand, unexpectedly it showed that about $43 \%$ of females with a U-shaped abdomen had immature ovaries at stages I or II (Fig. 4). This result suggests that ovarian maturation cannot be determined precisely by morphological observation of the abdomen. However, the initiation of vitellogenesis could be identified by external observation of the ovary without examining ovarian stage histologically. Therefore, external observation of the ovarian color would enables crab growers, aquaculturists, fishermen and fisheries managers to reduce time and cost for determining whether female S. paramamosain reaches ovarian maturity.

\section{Acknowledgements}

The authors thank to Dr. Toyoji Kaneko, Department of Aquatic Bioscience, The University of Tokyo, for his kind support and guideline in aspect of the histological study. The authors also wish to thank Mr. Oo, Mr. Chouvanan and particularly to Yasmin Mostari for assistance with crab sampling and measurement.

\section{References}

1. D.J. Machintosh, C. Thongkum, K. Swamy, C. Cheewasedtham and N. Paphavisit, Aqua. Fish. Manag. 24, 261 (1993).

2. S. Moser, D.J. Macintosh, S. Pripanapong and N. Tongdee, Mar. Fresh. Res. 53, 1083 (2002). doi:10.1071/MF01048

3. C.P. Keenan, P.F.J. Davie and D.L. Mann, The Raffles Bull. Zoo. 46, 217 (1998).

4. S. Moser, D.J. Macintosh, S. Laoprasert and N. Tongdee, Fish. Res. 71: 27 (2005). doi:10.1016/j.fishres.2004.07.008

5. J.L. Overton and D.J. Macintosh, J. Crus. Biol. 22, 790 (2002).

6. Bay of Bengal Program (BOBP), In Report of the seminar on the mud crab culture and trade, Surat Thani, Thailand, Angell, C.A. (ed.), Madras, India, BOBP/REP/51 (1992).

7. S. Poovachiranon, In Report of the seminar on mud crab culture and trade, Angell, C.A. (ed.), Bay of Bengal Programme, Madras. BOBP/REP/51, 49 (1992).

8. W.D. Robertson and A. Kruger, Estuarine, Coastal and Shelf Science 39, 185 (1994). doi:10.1006/ecss.1994.1057

9. S. D. Onyango, Wetland Ecology and management 10, 257 (2002).

10. E.T. Quintitio, J. de Pedro and Fe D. Parado-Estepa, Aquaculture research 38, 1434 (2007).

11. M.S. Islam, K. Kodama and H. Kurokura, Mar. Biol. Res. (in press) (2009).

12. U. Thampanya, J.E. Vermaat and C.M. Duarte, Mar. Ecol. Prog. Ser. 237, 111 (2002). doi:10.3354/meps 237111

13. S. Boromthanarath, S. Cobb, and V. Lee, Coastal Resources Institute, Prince of Songkla University (1991).

14. S. Koolkalya, T. Thapanand and S. Tunkijjanujij, Fish. Manag. Ecol. 13, 391 (2006). doi:10.1111/j.1365-2400.2006.00518.x

15. M. Minagawa, J-R. Chiu, M. Kudo, F. Ito, and F. Takashima, Mar. Biol. 115, 613 (1993). doi:10.1007/BF00349369

16. C. Lanteigne, P.G. Benninger and C. Gionet, Journal of Crustacean Biology 16, 501 (1996). doi: $10.2307 / 1548740$

17. B. Tiensongrusmee and B. Pratoomchat, The Thailand Research Fund, Bangkok, Thailand (in Thai) (2002). 
18. K. Kodama, T. Shimizu, T. Yamakawa, and I. Aoki, Fish. Sci. 70, 734 (2004). doi:10.1111/j.1444-2906.2004.00866.x

19. S. De Lestang, N.G. Hall and I.C. Potter, Fish. Bull. 101, 745 (2003).

20. K. Hamasaki, H. Imai, N. Akiyama and K. Fukunaga, Fisheries Science 70, 988 (2004). doi:10.1111/j.1444-2906.2004.00898.x

21. Y.X. Cheng, Journal of Zoology (Journal title in Chinese), 48, 86 (2003).

22. P.T. Johnson (CBS Educational and Professional Publishing, New York, USA, 1980) 440 pp.

23. I. Yano, Mar. Biol. 99: 547 (1988). doi:10.1007/BF00392562 